\title{
Density-Dependent Habitat Selection in a Growing Threespine Stickleback Population
}

\author{
Ulrika Candolin and Marita Selin \\ Department of Biosciences, University of Helsinki, P.O. Box 65, 00014 Helsinki, Finland \\ Correspondence should be addressed to Ulrika Candolin, ulrika.candolin@helsinki.fi \\ Received 19 March 2012; Revised 19 April 2012; Accepted 19 April 2012 \\ Academic Editor: Thomas Iliffe
}

Copyright (C) 2012 U. Candolin and M. Selin. This is an open access article distributed under the Creative Commons Attribution License, which permits unrestricted use, distribution, and reproduction in any medium, provided the original work is properly cited.

\begin{abstract}
Human-induced eutrophication has increased offspring production in a population of threespine stickleback Gasterosteus aculeatus in the Baltic Sea. Here, we experimentally investigated the effects of an increased density of juveniles on behaviours that influence survival and dispersal, and, hence, population growth - habitat choice, risk taking, and foraging rate. Juveniles were allowed to choose between two habitats that differed in structural complexity, in the absence and presence of predators and conspecific juveniles. In the absence of predators or conspecifics, juveniles preferred the more complex habitat. The preference was further enhanced in the presence of a natural predator, a perch Perca fluviatilis (behind a transparent Plexiglas wall). However, an increased density of conspecifics relaxed the predator-enhanced preference for the complex habitat and increased the use of the open, more predator-exposed habitat. Foraging rate was reduced under increased perceived predation risk. These results suggest that densitydependent behaviours can cause individuals to choose suboptimal habitats where predation risk is high and foraging rate low. This could contribute to the regulation of population growth in eutrophicated areas where offspring production is high.
\end{abstract}

\section{Introduction}

Individuals are usually forced to balance costs against benefits when choosing a habitat $[1,2]$. Structurally complex habitats are often more favourable than open habitats, as they provide more resources and better refuges against predators [3-5]. However, complex habitats can also be costly if they harbour more predators and competitors than open habitats $[6,7]$. In addition, the costs and benefits of choosing a habitat depend on what other individuals in the population are doing [8-10]. The profitability of a habitat decreases the more individuals that occupy it, because of a reduction in the amount of resources available per individual. As high quality habitats become saturated, more and more individuals are forced to occupy poor-quality habitats $[11,12]$. Interactions among individuals will then influence habitat selection, and, thus, density-dependent processes will affect individual fitness and the temporal and spatial distribution of the population.
Human activities are currently altering habitats at an unprecedented rate and scale around the world. The consequences that this will have for the populations that were well adapted to the past conditions are poorly known. An environment that is changing rapidly because of human activities is the Baltic Sea. Increased input of nutrients is enhancing primary production, which is altering habitat structure and water turbidity $[13,14]$. This has been found to improve the reproductive success of threespine sticklebacks Gasterosteus aculeatus breeding in shallow coastal areas. Enhanced growth of filamentous algae and phytoplankton reduces visibility, which allows more stickleback males to establish breeding territories within an area [15-17] and also enhances their hatching success [18]. Males care alone for their offspring, and reduced visibility lowers the risk of predation and reduces intrusions by competing males, which allows males to allocate time from offspring defence to offspring care, that is, to fan more oxygen-rich water into the nest [18]. These positive effects of eutrophication 
on offspring production could favour population growth [19]. Increased primary production could also have negative effects on population growth by reducing oxygen levels at night time, favouring the growth of toxic algae species, and increasing the sedimentation of dead organic material. However, recent work indicates that stickleback populations in the Baltic Sea are growing [20].

The ultimate effect of an increased offspring production on population growth depends on offspring survival and dispersal. Interactions among individuals and densitydependent processes are expected to influence these demographic components and, hence, regulate population growth. We investigated if habitat choice, risk taking, and foraging rate of offspring depend on the density of individuals, and, thus, if density-dependent processes could potentially contribute to the regulation of population growth. Threespine sticklebacks migrate in spring from deeper water to shallow coastal waters to breed [21]. The adults die at the end of the breeding season, but the hatched juveniles stay in the shallow waters until late autumn when they migrate to deeper waters (personal observation). The highest mortality occurs in the youngest age classes, as juveniles are highly vulnerable to predation and starvation [22, 23]. Thus, density-dependent juvenile behavior could have profound effects on mortality, fecundity, and dispersal of individuals and, hence, be an important component in the regulation of population growth [24].

To determine the effect of juvenile density on behaviours that influence population growth-habitat choice, risk taking, and foraging rate-we first allowed juveniles to choose between two habitats differing in structural complexity in the presence and absence of predators and conspecifics. The structural complexity of the habitats of the Baltic Sea is currently changing because of an increased growth of filamentous algae [14]. We then determined if the choice of a habitat influences the activity levels and foraging efficiency of the juveniles.

\section{Materials and Methods}

First-generation offspring $0+$ from a threespine stickleback population originating from the Baltic Sea close to Tvärminne Zoological station were raised in the laboratory (30 families). The juveniles were housed in mixed families (containing individuals from several families) in large flow through containers that contained both open and vegetated areas, on $6: 18$ light: dark cycle at $12^{\circ} \mathrm{C}$. They were fed with Artemia nauplii and chironomid larvae at least once a day. The juveniles were 5 months old $\left(L_{S}: 3.8 \pm 0.4 \mathrm{~cm}\right.$; mean \pm SD) when used in the experiment. The predators, perch Perca fluviatilis, were caught from lake Tuusula (close to Helsinki) with a hand trawl and transported to the University of Helsinki. They were kept in large holding tanks at a density of 4 fish/100-litre for a maximum of 4 weeks, at a temperature of $14^{\circ} \mathrm{C}$. They were fed chironomid larvae twice a week.

On the day before the experiment started, the juveniles were transferred from the containers to holding tanks $(100 \times$ $40 \times 30 \mathrm{~cm}$ ). The tanks had a temperature of $14^{\circ} \mathrm{C}$ and a density of 10 fish/100-litre. At the end of the experiment, the juveniles were returned to the flow through containers, and the perch returned to the lake.

2.1. Experiment 1: Habitat Selection. Juvenile sticklebacks were allowed to choose between two habitats that differed in algae cover, in the presence and absence of a predator (behind a Plexiglas wall) and conspecifics. An aquarium $(70 \times 40 \times$ $30 \mathrm{~cm})$ was divided into a predator section $(70 \times 16 \mathrm{~cm})$ and a stickleback section $(70 \times 24 \mathrm{~cm})$, using a transparent Plexiglas partition (Figure 1). Olfactory contact between the predator and the stickleback sections was allowed through small holes in the partitioning sheet. The bottom was covered with $2 \mathrm{~cm}$ of sand. In the stickleback section, an open and a vegetated habitat was created by adding eight bunches of artificial algae to one half of the section $(35 \times 24 \mathrm{~cm})$ while leaving the other half open (Figure 1). Each bunch of algae consisted of 32 thin, green, $20 \mathrm{~cm}$ long polypropylene strings. The artificial algae mimicked filamentous algae, and the density represented the density of algae found in nature. Artificial algae was used to ensure that only the structural complexity of the habitat was manipulated and no other potential effects of algae occurred. The temperature of the water was $14^{\circ} \mathrm{C}$.

A stickleback juvenile was placed in a transparent box $(19 \times 13 \times 11 \mathrm{~cm})$ with an open bottom in the middle of the stickleback section. After $10 \mathrm{~min}$ of acclimatization, the juvenile was carefully released by lifting the transparent box, without disturbing the water, and its choice of habitat was recorded 15, 30,60,120,180, and $1380 \mathrm{~min}(23 \mathrm{~h})$ after release. The observations were performed behind a blind with observation holes to minimize disturbances. Each juvenile was exposed to four treatments, in a predetermined order that differed among replicates to prevent an effect of previous experience (all possible orders were used) alone, the presence of a predator, the presence of four conspecific juveniles, and the presence of both a predator and four conspecifics. The four treatments were performed on four consecutive days. The water was changed between treatments to prevent an effect of previous treatments through olfactory cues. The juvenile was marked by cutting the edge of one of the dorsal spines. In total, 28 juveniles were tested.

In the predator treatment, a live perch Perca fluviatilis, $15-17 \mathrm{~cm}$ standard length, was placed into the predator section one day before the experiment was performed. Perch is the main predator in the region from which the sticklebacks were caught (personal observation). Live perch predators had to be used, as sticklebacks habituate to model predators. In the high density treatment, four additional juveniles were placed into the aquarium at the same time as the focal juvenile, first enclosed in the transparent box and then released. The total number of juveniles in the vegetated habitat was recorded and divided by five to give the probability of a juvenile choosing the vegetated habitat.

The probability that a juvenile would stay in the vegetated habitat was calculated for each of the four treatments as the percent of the six observations in which the juvenile was observed in the vegetated habitat. For the high-density treatment, the mean of the probabilities of a juvenile staying in the vegetation during the six observations was used. Time 


\begin{tabular}{|c|c|c|}
\hline \multicolumn{3}{|r|}{ Predator } \\
\hline O & 0 & O \\
\hline & & O Juvenile(s) \\
\hline 0 & 0 & 0 \\
\hline
\end{tabular}

Figure 1: Experimental aquarium divided into a predator and a juvenile section using a Plexiglas divider. The vegetated habitat is to the left in the juvenile section.

did not influence the results as qualitatively similar results were gained when the analyses were restricted to only one or a few time periods, and time was hence not further considered in the analyses.

\subsection{Experiment 2: Foraging Success and Swimming Activity.} Habitat-dependent foraging success and swimming activity was determined by allowing juveniles to feed for $10 \mathrm{~min}$ in one of two habitats, open or vegetated, in the presence or absence of a predator. Using the aquarium described above, a vegetated habitat with the same vegetation density as in experiment 1 was created by adding artificial algae to the sticklebacks section $(70 \times 24 \mathrm{~cm}, 16$ bunches of artificial algae). The predator section, along the backside of the aquarium $(70 \times 16 \mathrm{~cm})$, was left open. In the open habitat treatment, no vegetation was added. All aquaria had $2 \mathrm{~cm}$ of sand on the bottom. The stickleback section was divided into three equal sized parts by marking two lines on the front side of the aquarium.

The juveniles were food deprived for 1 day prior to the experiment. Ten chironomid larvae were evenly distributed over the bottom, and a juvenile stickleback was placed in a transparent box in the middle of the aquarium. After $10 \mathrm{~min}$ of acclimatization, the juvenile was released and observed for $10 \mathrm{~min}$ to determine the number of worms eaten and swimming activity, measured as the number of times the fish crossed the lines marked on the frontside. The number of remaining prey was counted at the end of the experiment. The experiment was done in the presence and absence of a perch in the predator section, using a vegetated and an open habitat, with different juveniles for each treatment. Twenty replicates of each treatment were carried out, each time using different fish.

All data were tested for normality and homogeneity of variances, using Wilk-Shapiro and Bartlett's test for equal variances, respectively. Swimming activity, measured as the number of times the fish crossed the two lines, was squareroot transformed before analysis. When assumptions of normality were not met, nonparametric tests were employed.

\section{Results}

3.1. Habitat Selection. Stickleback juveniles favoured the vegetated habitat over the open habitat in the absence of predators and conspecifics (one sample $t$-test; $t_{27}=2.30$, $P=0.029$, Figure 2). The presence of a predator and/or

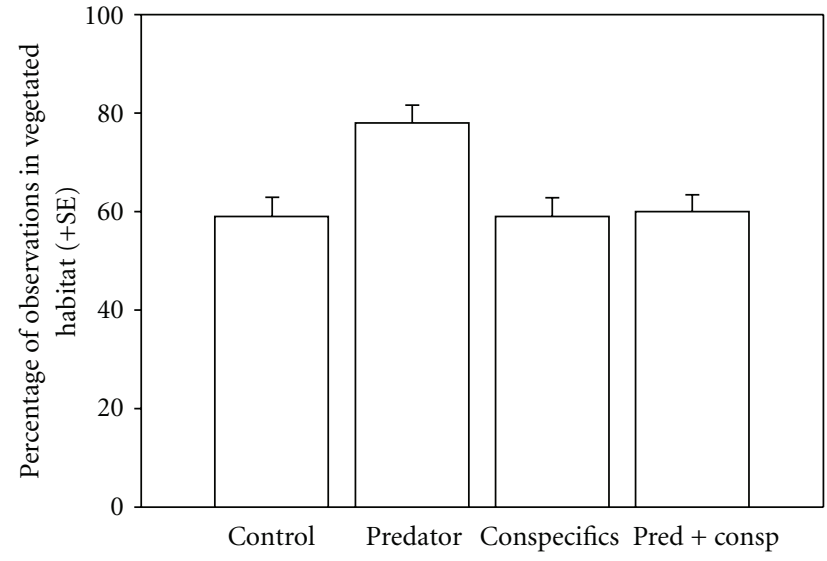

Figure 2: Preference of juvenile sticklebacks for the vegetated habitat in the absence and presence of a predator and four conspecifics. $N=28$ for each treatment.

conspecifics influenced habitat selection (repeated measures ANOVA, $\left.F_{3,25}=9.57, P<0.001\right)$. To determine which treatments differed from each other, paired comparisons were carried out. These revealed that the presence of a predator increased the use of the vegetated habitat when the juveniles were held singly (paired $t$-test for control against predator treatment, $\left.t_{27}=4.66, P<0.001\right)$ but had no effect on habitat selection when the juveniles were held in a group (paired $t$-test for conspecifics against predator + conspecifics, $t_{27}=0.28, P=0.79$, Figure 2). The presence of conspecifics had no effect on habitat selection in the absence of predators (paired $t$-test for control against conspecifics, $t_{27}=0.13, P=0.90$ ), but conspecifics reduced the use of the vegetated habitat in the presence of predators (paired $t$ test for predator against predator + conspecifics, $t_{27}=4.24$, $P<0.001$, Figure 2).

3.2. Foraging Success and Swimming Activity. Vegetation had no effect on foraging success, measured as the number of chironomid larvae eaten (Mann Whitney $U$-test, $U=734$, $N 1=N 2=40, P=0.49)$, but the presence of a predator reduced the number of larvae eaten $(U=590$, $P=0.029$, Figure 3 ). The juveniles were less active in the vegetation treatment, measured as number of times they crossed the marks on the frontside of the aquarium (twoway ANOVA; $F_{1,77}=26.56, P<0.001$, Figure 4 ). There was a nonsignificant tendency for the presence of a predator to reduce swimming activity $\left(F_{1,77}=3.50, P=0.065\right.$, Figure 4$)$, independent of habitat structure $\left(F_{1,76}=1.91, P=0.171\right)$.

\section{Discussion}

Threespine stickleback juveniles preferred the vegetated habitat over the open habitat in the absence of predators and conspecifics. The strength of the preference increased when a juvenile was exposed to a predator behind a Plexiglas wall. This was probably because the vegetated habitat offered better shelter against the predator than the open habitat. A preference for structurally more complex habitats in the face 


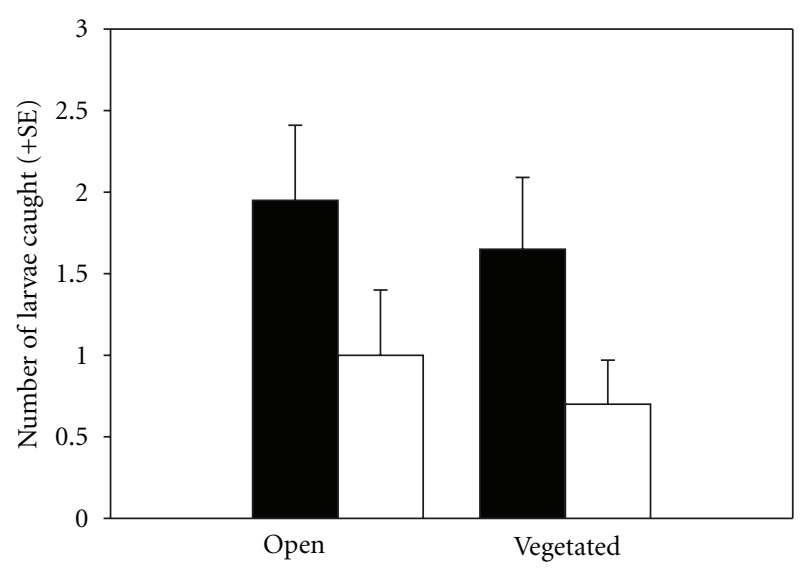

FIGURE 3: Number of chironomid larvae eaten by juvenile sticklebacks in two structurally different habitats, in the absence (black bar) and presence (white bar) of a predator. $N=20$ for each of the four treatments.

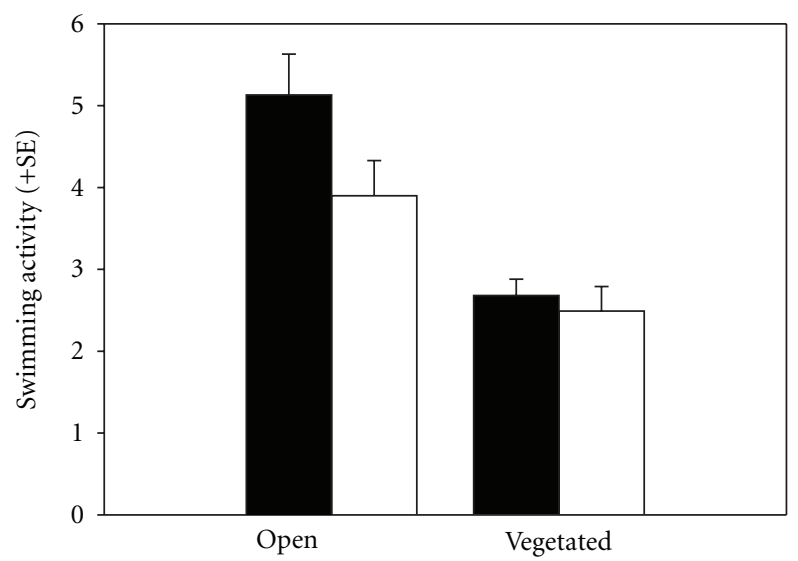

FIGURE 4: Swimming activity of juvenile sticklebacks (square-root transformed +0.5$)+$ SE in two structurally different habitats in the absence (black bar) and presence (white bar) of a predator. $N=20$ for each of the four treatments.

of predation is common among fishes, as high structural complexity usually impairs the ability of predators to detect or catch prey $[1,25,26]$. However, increased structural complexity also hinders the detection of predators and can increase their density. Thus, prey has to carefully balance the costs and benefits of staying in each habitat [4, 27]. The preference of the stickleback juveniles for the more complex habitat appears beneficial, as the main predators of sticklebacks in the investigated area are perch and terns, Sterna hirundo and S. paradisaea (personal observation), which are visual predators. Perch are efficient piscivores in open areas [28], while birds detect and catch sticklebacks more easily when vegetation is missing or sparse (personal observation).

Interestingly, the predator-induced preference for the more complex habitat was density dependent. An increased density of juveniles reduced the use of the refuge during the predator exposure. The juveniles could have been forced to leave the refuge because of interindividual interactions, or, alternatively, benefitted from leaving the refuge because of the perception of less resources being available per individual in the refuge (food or space, although no food was provided), or a lower per capita mortality risk of venturing out of the refuge when density was higher also outside the refuge. Independent of which scenario, or scenarios, is true, the increased use of the open habitats is expected to increase predation rate on the population. The second experiment on foraging rate and activity found juveniles to reduce their foraging rate when exposed to predators, and they tended to be less active. This suggests that juveniles have to trade foraging for predator avoidance. In the field, juveniles may be forced to use the water column above the vegetation or migrate to areas with sparser vegetation when the density of juveniles increases. This could increase mortality or reduce fecundity, which could contribute to the regulation of the size of the population [29]. Thus, an increased use of predatorexposed areas under high offspring densities could offset the present increase in the reproductive output of the population $[15,18]$. However, investigations in the field or under more natural conditions are needed to confirm this.

An increased offspring production because of eutrophication [18] combined with an increased mortality of juveniles because of density-dependent processes could have evolutionary consequences. The strength of natural selection could increase and compensate for a recorded relaxation of sexual selection in eutrophied areas. Reduced visibility due to increased growth of algae has been found to relax sexual selection in sticklebacks by hampering careful mate choice and allowing dishonest sexual signalling [30-32]. As sexual selection is an important evolutionary force that can improve the genetic quality of a population and accelerate adaptation [33], relaxed sexual selection could have negative consequences for population fitness [34-38]. Thus, an increased strength of viability selection when offspring production increases could compensate for relaxed sexual selection. This could accelerate genetic adaptation to the eutrophied conditions.

To determine if density-dependent habitat choice of sticklebacks does regulate population growth under eutrophied conditions, field experiments and monitoring are needed. Moreover, the question of the relative strength of sexual selection, and other components of natural selection in shaping populations during environmental change would deserve more attention [39]. The ability of populations to adapt to changed conditions, such as eutrophication, depends ultimately on genetic changes, which relies on the operation of natural selection. A challenge of future work is to consider the many different factors and pathways that influence population size and viability in changing environments.

\section{Acknowledgments}

The authors thank Julia Crombez and Huseyin Sasi for assistance with the experimental procedures, and WANS and the Academy of Finland for financial support. The 
experimental procedures comply with the laws of the country in which they were performed. They were approved by the Animal Care Committee of the University of Helsinki (no. 133-05).

\section{References}

[1] E. E. Werner, G. G. Mittelbach, D. J. Hall, and J. F. Gilliam, "Experimental tests of optimal habitat use in fish: the role of relative habitat profitability," Ecology, vol. 64, no. 6, pp. 15251539, 1983.

[2] A. I. Houston and J. M. McNamara, Models of Adaptive Behaviour, Cambridge University Press, Cambridge, Mass, USA, 1999.

[3] A. J. Kohn and P. J. Leviten, "Effect of habitat complexity on population density and species richness in tropical intertidal predatory gastropod assemblages," Oecologia, vol. 25, no. 3, pp. 199-210, 1976.

[4] B. J. Downes, P. S. Lake, E. S. G. Schreiber, and A. Glaister, "Habitat structure and regulation of local species diversity in a stony, upland stream," Ecological Monographs, vol. 68, no. 2, pp. 237-257, 1998.

[5] U. Candolin and H. R. Voigt, "Do changes in risk-taking affect habitat shifts of sticklebacks?" Behavioral Ecology and Sociobiology, vol. 55, no. 1, pp. 42-49, 2003.

[6] A. Sih, "To hide or not to hide? Refuge use in a fluctuating environment," Trends in Ecology \& Evolution, vol. 12, pp. 375376, 1997.

[7] L. Persson and P. Eklöv, "Prey refuges affecting interactions between piscivorous perch and juvenile perch and roach," Ecology, vol. 76, no. 1, pp. 70-81, 1995.

[8] P. L. Munday, G. P. Jones, and M. J. Caley, "Interspecific competition and coexistence in a guild of coral-dwelling fishes," Ecology, vol. 82, no. 8, pp. 2177-2189, 2001.

[9] S. H. Alonzo, "State-dependent habitat selection games between predators and prey: the importance of behavioural interactions and expected lifetime reproductive success," Evolutionary Ecology Research, vol. 4, no. 5, pp. 759-778, 2002.

[10] P. J. Schofield, "Habitat selection of two gobies (Microgobius gulosus, Gobiosoma robustum): influence of structural complexity, competitive interactions, and presence of a predator," Journal of Experimental Marine Biology and Ecology, vol. 288, no. 1, pp. 125-137, 2003.

[11] E. A. Whiteman and I. M. Côté, "Individual differences in microhabitat use in a Caribbean cleaning goby: a buffer effect in a marine species?" Journal of Animal Ecology, vol. 73, no. 5, pp. 831-840, 2004.

[12] J. R. Post, M. R. S. Johannes, and D. J. McQueen, "Evidence of density-dependent cohort splitting in age-0 yellow perch (Perca flavescens): potential behavioural mechanisms and population-level consequences," Canadian Journal of Fisheries and Aquatic Sciences, vol. 54, no. 4, pp. 867-875, 1997.

[13] S. Råberg, R. Berger-Jönsson, A. Björn, E. Granéli, and L. Kautsky, "Effects of Pilayella littoralis on Fucus vesiculosus recruitment: implications for community composition," Marine Ecology Progress Series, vol. 289, pp. 131-139, 2005.

[14] M. Raateoja, J. Seppälä, H. Kuosa, and K. Myrberg, "Recent changes in trophic state of the Baltic Sea along SW coast of Finland," Ambio, vol. 34, no. 3, pp. 188-191, 2005.

[15] U. Candolin, "Effects of algae cover on egg acquisition in male three-spined stickleback," Behaviour, vol. 141, no. 11-12, pp. 1389-1399, 2004.
[16] U. Candolin and H. R. Voigt, "Correlation between male size and territory quality: consequence of male competition or predation susceptibility?” Oikos, vol. 95, no. 2, pp. 225-230, 2001.

[17] J. Heuschele and U. Candolin, "Reversed parasite-mediated selection in sticklebacks from eutrophied habitats," Behavioral Ecology and Sociobiology, vol. 64, no. 8, pp. 1229-1237, 2010.

[18] U. Candolin, J. Engström-Öst, and T. Salesto, "Humaninduced eutrophication enhances reproductive success through effects on parenting ability in sticklebacks," Oikos, vol. 117, no. 3, pp. 459-465, 2008.

[19] U. Candolin, "Population responses to anthropogenic disturbance: lessons from three-spined sticklebacks Gasterosteus aculeatus in eutrophic habitats," Journal of Fish Biology, vol. 75, no. 8, pp. 2108-2121, 2009.

[20] L. Ljunggren, A. Sandström, U. Bergström et al., "Recruitment failure of coastal predatory fish in the Baltic Sea coincident with an offshore ecosystem regime shift," ICES Journal of Marine Science, vol. 67, no. 8, pp. 1587-1595, 2010.

[21] U. Candolin and H. R. Voigt, "Size-dependent selection on arrival times in sticklebacks: why small males arrive first," Evolution, vol. 57, no. 4, pp. 862-871, 2003.

[22] M. S. Webster, "Role of predators in the early post-settlement demography of coral-reef fishes," Oecologia, vol. 131, no. 1, pp. 52-60, 2002.

[23] E. D. Houde, "Mortality," in Fisheries Science. The Unique Contributions of Early Life Stages, L. A. Fuiman and R. G. Werner, Eds., pp. 64-87, Blackwell Publishing, Oxford, UK, 2002.

[24] U. Tuomainen and U. Candolin, "Behavioural responses to human-induced environmental change," Biological Reviews, vol. 86, no. 3, pp. 640-657, 2011.

[25] J. F. Savino and R. A. Stein, "Behavioural interactions between fish predators and their prey: effects of plant density," Animal Behaviour, vol. 37, no. 2, pp. 311-321, 1989.

[26] S. Diehl and P. Eklöv, "Effects of piscivore-mediated habitat use on resources, diet, and growth of perch," Ecology, vol. 76, no. 6, pp. 1712-1726, 1995.

[27] D. J. Ferrell and J. D. Bell, "Differences among assemblages of fish associated with Zostera capricorni and bare sand over a large spatial scale," Marine Ecology Progress Series, vol. 72, no. 1-2, pp. 15-24, 1991.

[28] P. Eklöv and S. Diehl, "Piscivore efficiency and refuging prey: the importance of predator search mode," Oecologia, vol. 98, no. 3-4, pp. 344-353, 1994.

[29] W. J. Sutherland and K. Norris, "Behavioural models of population growth rates: implications for conservation and prediction," Philosophical Transactions of the Royal Society B, vol. 357, no. 1425, pp. 1273-1284, 2002.

[30] J. Engström-Öst and U. Candolin, "Human-induced water turbidity alters selection on sexual displays in sticklebacks," Behavioral Ecology, vol. 18, no. 2, pp. 393-398, 2007.

[31] U. Candolin, T. Salesto, and M. Evers, "Changed environmental conditions weaken sexual selection in sticklebacks," Journal of Evolutionary Biology, vol. 20, no. 1, pp. 233-239, 2007.

[32] B. B. M. Wong, U. Candolin, and K. Lindström, "Environmental deterioration compromises socially enforced signals of male quality in three-spined sticklebacks," American Naturalist, vol. 170, no. 2, pp. 184-189, 2007.

[33] U. Candolin and J. Heuschele, "Is sexual selection beneficial during adaptation to environmental change?" Trends in Ecology and Evolution, vol. 23, no. 8, pp. 446-452, 2008. 
[34] A. P. Møller and R. V. Alatalo, "Good-genes effects in sexual selection," Proceedings of the Royal Society B, vol. 266, no. 1414, pp. 85-91, 1999.

[35] P. D. Lorch, S. Proulx, L. Rowe, and T. Day, "Conditiondependent sexual selection can accelerate adaptation," Evolutionary Ecology Research, vol. 5, no. 6, pp. 867-881, 2003.

[36] M. C. Whitlock, "Fixation of new alleles and the extinction of small populations: drift load, beneficial alleles, and sexual selection," Evolution, vol. 54, no. 6, pp. 1855-1861, 2000.

[37] A. F. Agrawal, "Sexual selection and the maintenance of sexual reproduction," Nature, vol. 411, no. 6838, pp. 692-695, 2001.

[38] O. Seehausen, "Conservation: losing biodiversity by reverse speciation,” Current Biology, vol. 16, no. 9, pp. R334-R337, 2006.

[39] U. Candolin and B. B. M. Wong, "Sexual selection in changing environments: consequences for individuals and populations," in Behavioural Responses to a Changing World: Causes and Consequences, U. Candolin and B. B. M. Wong, Eds., pp. 201215, Oxford University Press, Oxford, UK, 2012. 

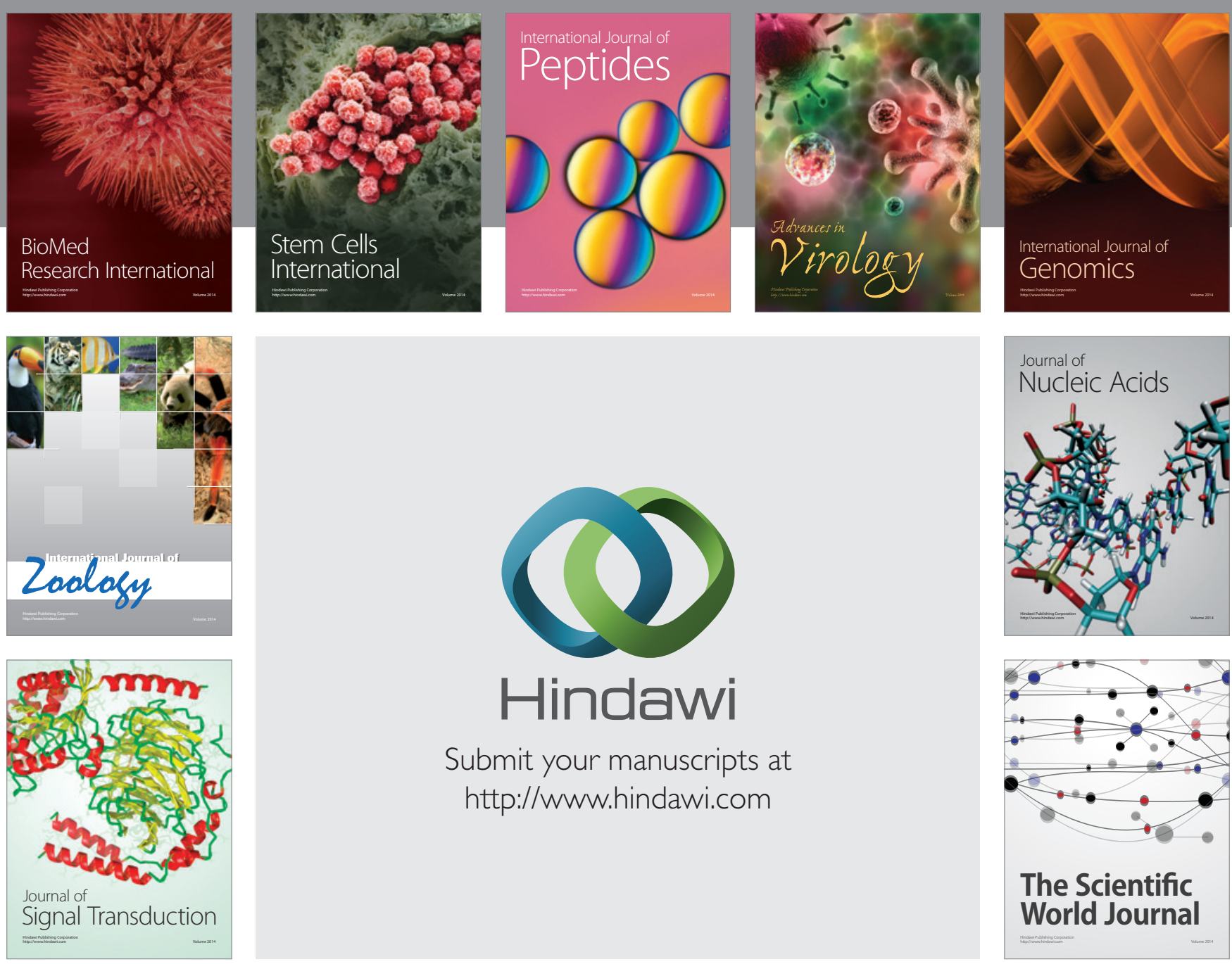

Submit your manuscripts at

http://www.hindawi.com
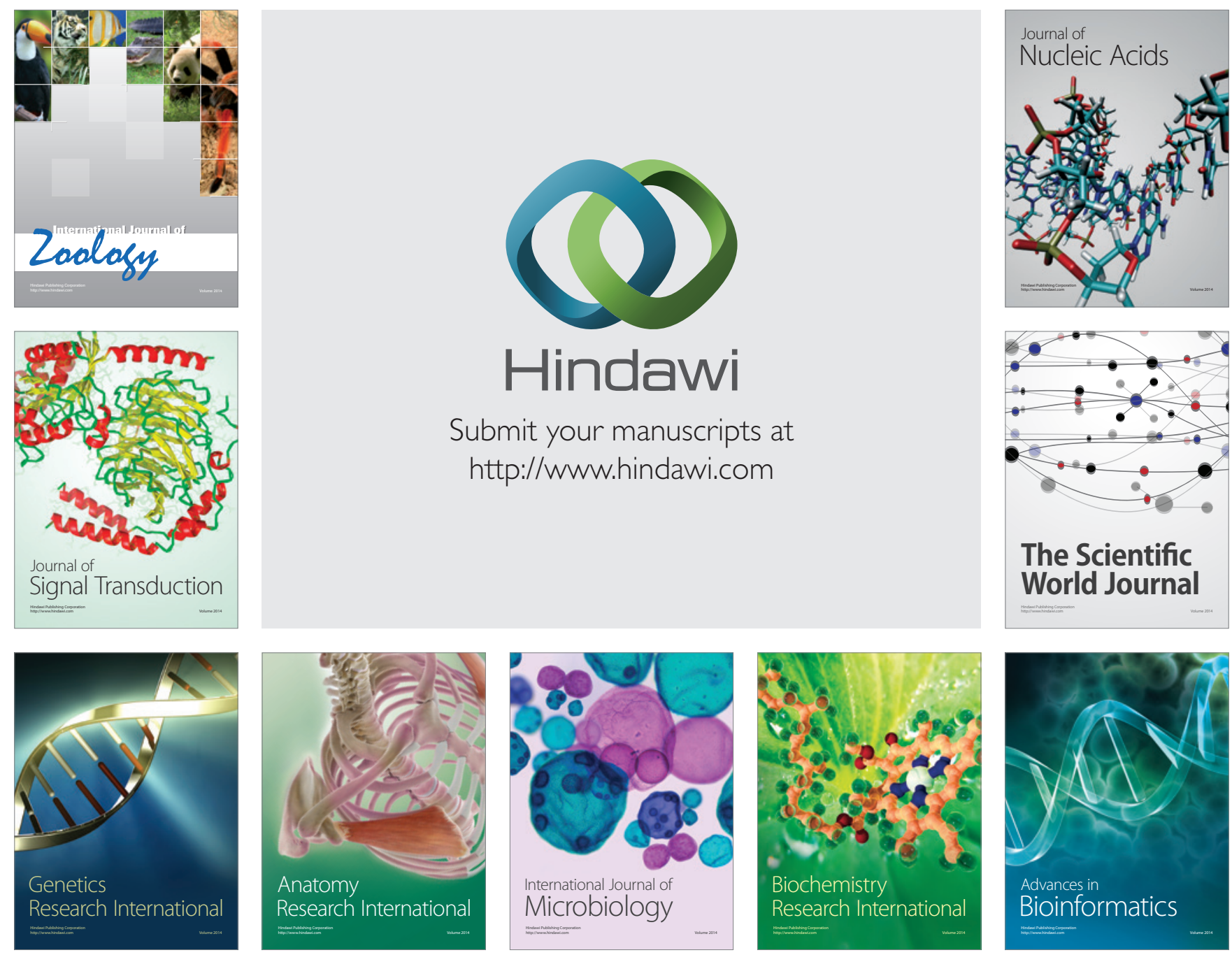

The Scientific World Journal
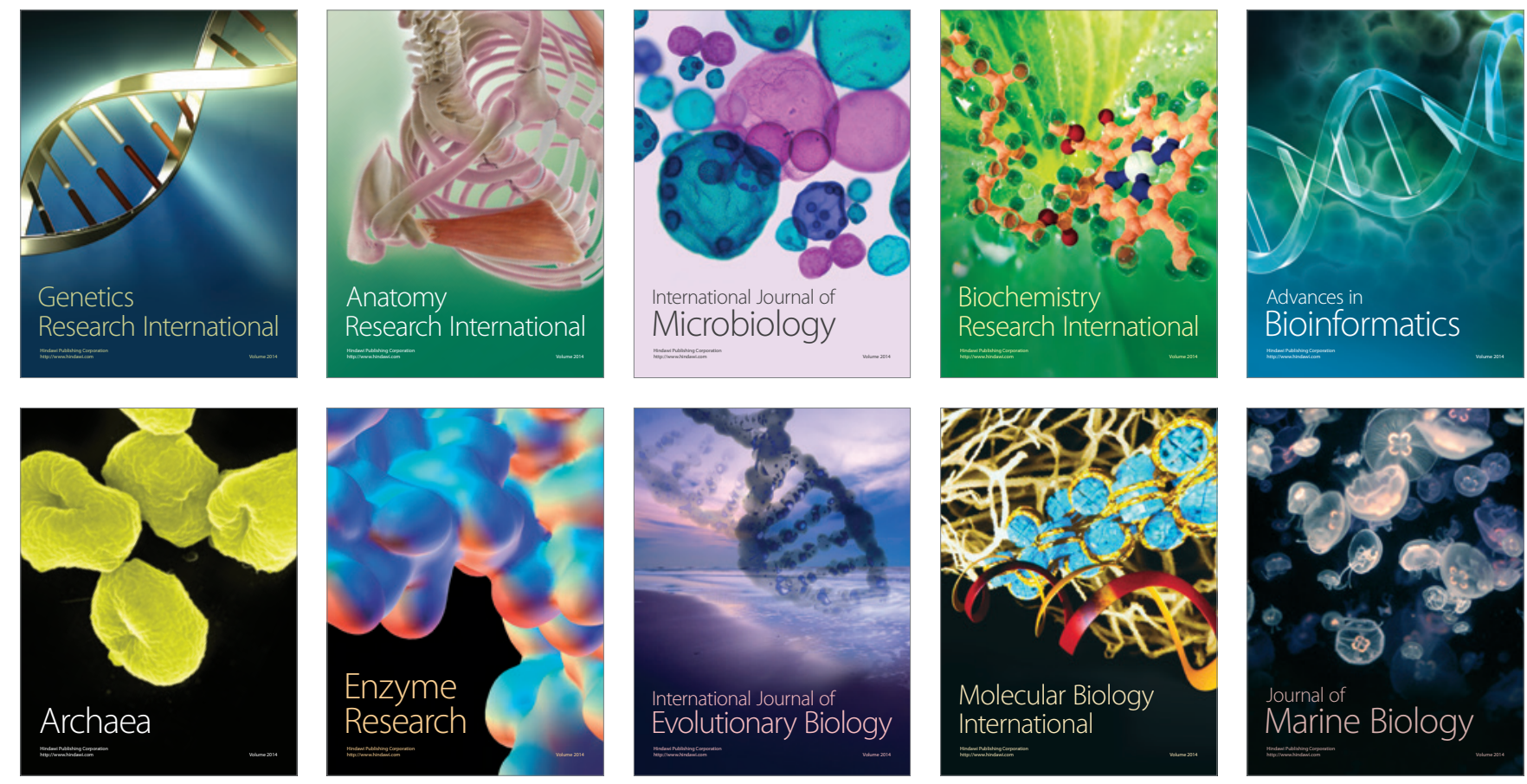